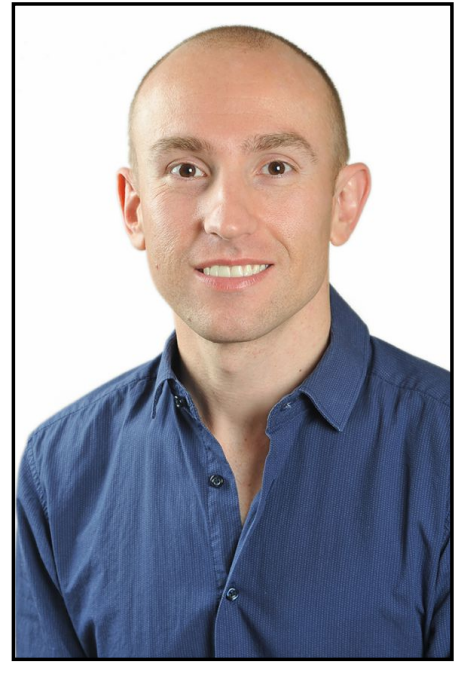

\title{
The 1st International Congress of Hypertension in Children and Adolescents (ICHCA)
}

\author{
Ruan Kruger \\ Chair, ISH New Investigator Committee (NIC) \\ Hypertension in Africa Research Team (HART) \\ South African Medical Research Council Unit for Hypertension and \\ Cardiovascular Disease \\ North-West University, South Africa
}

The burden of hypertension in children and adolescents has become a true concern. From the recent 2016 European Society of Hypertension Guidelines for the Management of High Blood Pressure in Children and Adolescents, ${ }^{1}$ there was a call to action paediatric hypertension which contributes to the current epidemic of cardiovascular disease. A global effort to improve the identification and treatment of high blood pressure among children and adolescents is therefore anticipated.

In a systematic review published in the Lancet, the prevalence of hypertension and slightly elevated blood pressure was $5.5 \%$ and $12.7 \%$ respectively, with overweight and obesity being important risk factors. ${ }^{2}$ These findings have major implications for health systems as these young people are likely to track to adult hypertension. With these important citations in the backdrop, the first International Congress of Hypertension in Children and Adolescents (ICHCA) was born. In a combined effort, Professors Empar Lurbe (Spain), Brian Rayner (South Africa) and Daniel Feig (USA) hosted this exciting congress in the charming setting of Valencia, Spain on 9th- 11th February 2018.

Renowned speakers invited to this meeting included amongst others Professors Anna Dominiczak (UK), Nicholas Webb (UK), Kennedy Cruickshank (UK), Denes Pall (Hungary), Josep Redon (Spain), Mark Mitsnefes (USA), Elke Wühl (Germany), and Mieczyslaw Litwin (Poland). Julie Ingelfinger (USA), Professor of Pediatrics at Harvard Medical School, Senior consultant in Pediatric Nephrology at Mass General Hospital for Children at Massachusetts General Hospital, and Deputy Editor of the New England Journal of Medicine enlightened us with the congress keynote titled Facing the challenges of hypertension in children and adolescents. The congress also included a small selection of e-Posters and short scientific communications from peer-reviewed abstracts.

This first ICHCA meeting was attended by 123 delegates from 46 countries endorsed by 22 partners and societies. Whether this will become an annual or biennial meeting is still to be announced, but mention was made that the second meeting will take place in 2019, with no further information confirmed.

Be sure to keep this congress on your list of meetings to attend!

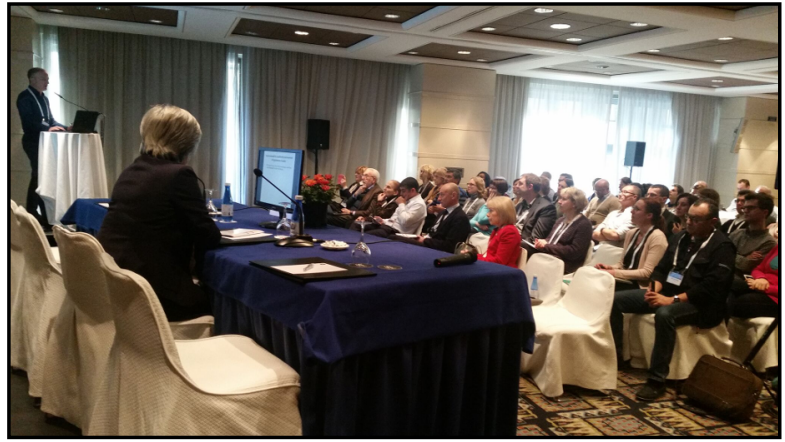

\author{
Ruan Kruger \\ ruan.kruger@me.com
}

\section{REFERENCES:}

1. Lurbe E, Agabiti-Rosei E, Cruickshank JK, Dominiczak A, Erdine S, Hirth A, et al. 2016 European Society of Hypertension guidelines for the management of high blood pressure in children and adolescents. J Hypertens. 2016;34(10):1887-920. DOI: $10.1097 / \mathrm{HJH} .0000000000001039$.

2. Noubiap JJ, Essouma M, Bigna JJ, Jingi AM, Aminde LN, Nansseu JR. Prevalence of elevated blood pressure in children and adolescents in Africa: a systematic review and meta-analysis. The Lancet Public Health.2(8):e375-e86.

DOI: 10.1016/S2468-2667(17)30123-8 